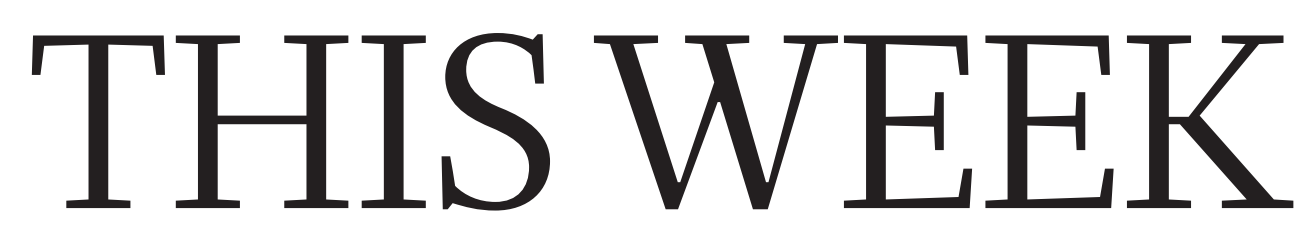

EDITORIALS

CONTRACEPTION Science prevails in long-running battle over Plan B p.272
WORLD VIEW Patents and secrecy are yesterday's route to innovation $\mathbf{p . 2 7 3}$

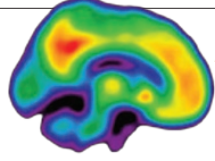

ALZHEIMER'S Genetic clue to brain plaque formation $\mathbf{p . 2 7 5}$

\title{
Risk management
}

\section{A project to pool data and tools to calculate earthquake hazards is an important milestone, but it will be down to individuals to decide how to interpret and respond to those risks.}

$\mathrm{T}$ The number of people living in earthquake zones is rising year on year, making the mitigation of seismic risk more important than ever. So let's hear two cheers for the consortium of Earth and social scientists and engineers that is set to release a Global Earthquake Model (GEM) in the coming year (see page 290).

Only two cheers? Although the project's worldwide scale matches its ambition, whether it will save lives depends on how its data and tools are used locally. And, as shown by the conviction of six scientists for misreporting the risk of an earthquake that hit L'Aquila, Italy, in 2009 , it will also depend on how that information is communicated to decision-makers.

The GEM project addresses a need: around the world most seismicsafety workers must cobble together information from a host of sources to work out which locations are the most dangerous. In countries such as Indonesia and Peru, access to seismic information is limited. The digital platform, global databases and suite of software tools offered by GEM will make it much easier for hazard analysts and emergency planners to assess risk. But that is only the start.

Hazard assessment is a specialist trade and open to misinterpretation. GEM's critics contend that the project's authoritative plots and snazzy graphics might generate a false sense of security in the robustness of the results. Feed in a different set of historical quakes or tweak the parameters, and the maps change. Such difficulties are, rightly, hotly debated in the earthquake-hazard community, and better methods may emerge as a result of bigger studies made possible by GEM. Conveying uncertainties will be essential. But disagreement does not diminish risk.

The sharing of knowledge and best practice could help to tip the balance and persuade governments and communities to take action to improve their building stock, and not view earthquakes simply as 'acts of God' about which little can be done. A worldwide network such as GEM could be a conduit. Its standard tools might bring some sanity to seismic-risk analyses in countries such as Italy, where researchers are cowed, and in Greece, where investment is being diverted away from safety to dubious studies of quake prediction.

To be useful, the data should be as comprehensive as possible. Governments and universities worldwide should embrace transparency and publish and pool their seismic, planning and socio-economic data within GEM.

Translation of the results into action should be a priority. In addition to stacking its boardroom with more managers as its membership grows, GEM should extend its training of scientists and practitioners to spread knowledge of GEM and seismic-risk modelling on the ground, where it matters most. As training workshops under way in several regions already show, a major part of GEM's legacy lies in bringing together previously unpublished local data under one umbrella. Fellowships for students and postdocs to work with GEM, as well as the recruitment and instruction of more trainers, would be good steps.

Once the inevitable happens and a major earthquake strikes, GEM should learn from it. Part of the project's legacy must be for the seismic-hazard community - and those working on other hazards - to evaluate how well its information reaches those on the ground and whether it helps to prevent deaths. Given the large sums of money

"Governments and universities worldwide should pool their seismic, planning and socio-economic data." the World Bank and several national governments, GEM is more resistant to litigation than individual researchers or a committee in one country, such as the scientists involved in the L'Aquila case. As ever, it is individuals who will have to make the difficult decisions about how to report and respond to quake risk. GEM's value is in helping practitioners to speak the same language. -

\section{Brain blast}

\section{DIY attempts at electrical brain stimulation to improve cognition are to get easier.}

B uyer beware. For US $\$ 249$ a company in the United States is promising to send curious and competitive players of computer games an unusual headset. The device, the company claims, will convert electronic gamers into electronic-gamers. At the touch of a button, the headset will send a surge of electricity through their prefrontal cortex. It promises to increase brain plasticity and make synapses fire faster, to help gamers repel more space invaders and raid more tombs. And, according to the publicity shots on the website, it comes in a choice of red or black.

The company is accepting orders, but says that it will not ship its first headsets to customers until next month. Some are unwilling to wait. Videos on the Internet already show people who have cobbled together their own version with a 9-volt battery and some electrical wire. If you are not fussy about the colour scheme, other online firms already promise to supply the components and instructions you need to make your own. Or you could rummage around in the garage.

That's 'could' as in 'you might be able to', by the way; not 'could' as 